\title{
Superelastic Porous NiTi with Adjustable Porosities Synthesized by Powder Metallurgical Method
}

\author{
Xiangmei Liu, Shuilin Wu, K.W.K. Yeung, Z.S. Xu, C.Y. Chung, and Paul K. Chu
}

(Submitted February 14, 2012; in revised form June 14, 2012)

\begin{abstract}
The effects of cold compaction pressure, $\mathrm{TiH}_{2}$, and $\mathrm{NH}_{4} \mathrm{HCO}_{3}$ on the physical and mechanical properties of porous NiTi fabricated by capsule-free-hot isostatic pressing (CF-HIP) were investigated. The porosities vary from 20 to $48 \%$ depending on the pressure. Porous NiTi with as great as $42 \%$ porosity and irregular pores can be prepared by the addition of $\mathrm{TiH}_{2}$, whereas $48 \%$ porosity and circular pores can be achieved by $\mathrm{NH}_{4} \mathrm{HCO}_{3}$ addition. All the porous NiTi fabricated by CF-HIP using these three methods exhibit superelastic behavior that closely matches human bones.
\end{abstract}

Keywords implants, porous NiTi, powder metallurgy, superelastic

\section{Introduction}

Stainless steels and Ti-based alloys are used in the medical fields because of their high strength, good wear resistance, high corrosion resistance, and excellent biocompatibility (Ref 1-4). However, the high Young's moduli of these biometals impair bone regrowth when implanted in humans (Ref 4). Porous NiTi has recently become one of the most promising materials in surgical implants because of its open structure, low elastic modulus, high strength, good biocompatibility, and excellent superelasticity (SE) (Ref 5-10). The manufacturing processes and characteristics of porous NiTi have been reported (Ref 6, 10-18). For instance, Li et al. (Ref 11) and Chu et al. (Ref 12) have produced porous NiTi by combustion synthesis (CS). Unfortunately, the stressstrain curve obtained from their materials does not show an obvious stress plateau and the materials are brittle. Porous

This article is an invited paper selected from presentations at the International Conference on Shape Memory and Superelastic Technologies 2011, held November 6-9, 2011, in Hong Kong, China, and has been expanded from the original presentation.

Xiangmei Liu and Z.S. Xu, Ministry-of-Education, Key Laboratory for the Green Preparation and Application of Functional Materials, School of Materials Science and Engineering, Hubei University, Wuhan 430062, People's Republic of China; C.Y. Chung and Paul K. Chu, Department of Physics \& Materials Science, City University of Hong Kong, Tat Chee Avenue, Kowloon, Hong Kong, People's Republic of China; Shuilin Wu, Ministry-of-Education, Key Laboratory for the Green Preparation and Application of Functional Materials, School of Materials Science and Engineering, Hubei University, Wuhan 430062, People's Republic of China and Department of Physics \& Materials Science, City University of Hong Kong, Tat Chee Avenue, Kowloon, Hong Kong, People's Republic of China; and K.W.K. Yeung, Division of Spine Surgery, Department of Orthopaedics and Traumatology, The University of Hong Kong, Pokfulam, Hong Kong, People's Republic of China. Contact e-mails: shuilin.wu@gmail.com and paul.chu@cityu.edu.hk.
NiTi prepared by $\mathrm{Li}, \mathrm{Zhu}$, et al. employing elemental powder sintering (EPS) (Ref 13-15) exhibit low compression strength and low strain recovery. Kim et al. (Ref 16) have fabricated porous NiTi by self-propagating high temperature synthesis (SHS) and their materials also have relatively poor mechanical properties. The porous NiTi made by HIP by Lagoudas and Vandygriff (Ref 17) also shows low compression strength because of the irregular pore structure. Yuan et al. (Ref 18) have prepared recently a porous NiTi by CF-HIP that is used to improve the mechanical properties of ceramic materials while retaining adequate porosity of the as-pressed powders (Ref 19), but it is difficult to control the pore size, shape and distribution. To build up on our recent success (Ref 20), we report herein the production of porous NiTi by the CF-HIP with adjustable porosities, pore shape and size as well as good mechanical properties and excellent SE. We investigate the effects of the cold compaction pressure as well as addition of $\mathrm{TiH}_{2}$ and $\mathrm{NH}_{4} \mathrm{HCO}_{3}$ on the porous structure, phase components, superelastic behavior, and transformation temperature of the porous NiTi.

\section{Experimental Procedures}

Commercial elemental nickel $(50-75 \mu \mathrm{m})$, titanium (50-75 $\mu \mathrm{m}), \mathrm{TiH}_{2}(15-40 \mu \mathrm{m})$, and $\mathrm{NH}_{4} \mathrm{HCO}_{3}(20-100 \mu \mathrm{m})$ powders, all with purity of $99.5 \%$, were used in our study. Three different types of samples were fabricated by CF-HIP from different green compacts in order to assess the effects of the cold compaction pressure, $\mathrm{TiH}_{2}$, and $\mathrm{NH}_{4} \mathrm{HCO}_{3}$ on the porosity, pore size, shape, and distribution. Samples of type A were fabricated from fully mixed equiatomic $\mathrm{Ni}$ and $\mathrm{Ti}$ powders compacted at different cold pressures, and samples of type $\mathrm{B}$ were prepared from fully mixed $\mathrm{Ni}, \mathrm{Ti}$ and 9.0 wt. $\% \mathrm{TiH}_{2}$ powders with an atomic ratio of $1: 1$ of $\mathrm{Ni}$ to $\mathrm{Ti}$ at a cold compaction pressure of $200 \mathrm{MPa}$. Samples of type $\mathrm{C}$ were made from fully mixed equiatomic $\mathrm{Ni}$ and $\mathrm{Ti}$ powders with 30 wt. $\% \mathrm{NH}_{4} \mathrm{HCO}_{3}$ at the same pressure. The materials were mixed for $12 \mathrm{~h}$ using a horizontal universal ball mill with a speed of $100 \mathrm{rpm}$ and then pressed into green compacts in a steel mold with a diameter of $16 \mathrm{~mm}$ 
using a hydraulic press. For type $\mathrm{C}$, the corresponding green compacts were preheated at $200{ }^{\circ} \mathrm{C}$ for $2 \mathrm{~h}$ in a tube furnace under a continuous flow of pure argon to remove $\mathrm{NH}_{4} \mathrm{HCO}_{3}$. The green compacts were sintered in a HIP. Before sintering, the HIP chamber was evacuated and then backfilled with 99.995\% pure argon. At first, the argon pressure was raised to $100 \mathrm{MPa}$ at room temperature and then increased as the temperature increased. The argon pressure and temperature reached $150 \mathrm{MPa}$ and $1050{ }^{\circ} \mathrm{C}$ at the same time. The high pressure and temperature were kept for $3 \mathrm{~h}$ allowing sufficient diffusion of nickel and titanium.

The phases and microstructures of the porous NiTi samples were determined by x-ray diffraction (XRD, Siemens D500), optical microscopy (OLYMPUS BH2-UMA) and stereo optical microscopy (OLYMPUS SZX12). The general porosity of the samples was evaluated by the equation: $\varepsilon=\left(1-\frac{m}{\rho V}\right) \times 100(\%)$, where $m$ and $V$ are the mass and volume of porous samples, respectively, and $\rho$ is the theoretical density of NiTi of $6.45 \mathrm{~g} / \mathrm{cm}^{3}$ for bulk equiatomic NiTi. The samples for compression tests were machined into cylindrical bars $6 \mathrm{~mm}$ in diameter and $15 \mathrm{~mm}$ in length. The uniaxial compression tests were conducted at a constant displacement rate of $0.06 \mathrm{~mm} / \mathrm{min}$ under room temperature of about $22{ }^{\circ} \mathrm{C}$ on an Instron 4206 to investigate the compression strength and SE. The transformation temperature was determined using a differential scanning calorimetry (DSC) with a heating/cooling rate of $5{ }^{\circ} \mathrm{C} / \mathrm{min}$.
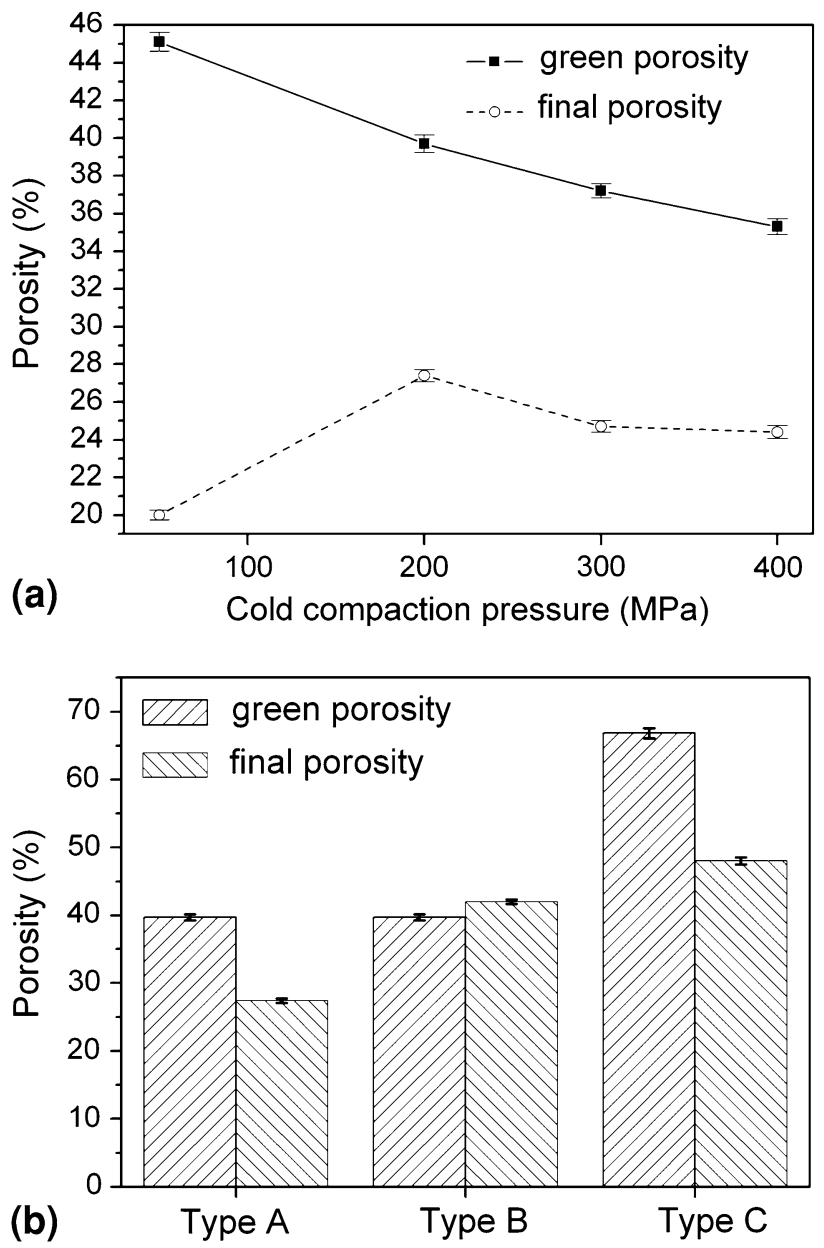

Fig. 1 Porosities of porous NiTi and corresponding green compacts: (a) type A, (b) comparison of types A, B, and C

\section{Results and Discussion}

Figure 1(a) shows the porosities of the type A samples and corresponding green porosities at different cold compaction pressures. The final porosity of the porous NiTi falls in the range of 20-28 vol.\%, indicating that the porosity is adjustable by changing the cold compaction pressure of the green compacts because the cold compaction pressure can alter the number, size and distribution of the original pores in the green compacts. Generally, the green porosity decreases with higher cold compaction pressure. However, the porous NiTi with the highest final porosity of about $28 \%$ was not sintered from the green compact at $50 \mathrm{MPa}$ but from the one at $200 \mathrm{MPa}$. It suggests that the porosity of the porous NiTi is not determined only by cold compaction and the subsequent hot pressure during CF-HIP also significantly influences the final porosity. In this study, the hot pressure was $150 \mathrm{MPa}$, much higher than the cold compaction pressure of $50 \mathrm{MPa}$, thereby inducing larger deformation of this sample during sintering at $1050{ }^{\circ} \mathrm{C}$. In comparison, with regard to the green compacts at $200 \mathrm{MPa}$, the hot pressure is close to the cold compaction pressure, and deformation is small during sintering. It is obvious that the final porosities of the samples are much lower than the corresponding green porosities (shown in Fig. 1a). This large drop is possibly due to the shrinkage of the original pores during CF-HIP. Figure 1(b) exhibits the difference in the porosity of the three types of samples and corresponding green compacts at a cold compaction pressure of $200 \mathrm{MPa}$. The final porosity of the type $\mathrm{B}$ samples rises to about $42 \%$. It is due to the formation of a large amount of $\mathrm{H}_{2}$ pores from the decomposition of $\mathrm{TiH}_{2}$ during CF-HIP process (Ref 15). These $\mathrm{H}_{2}$ pores favor the formation of open pores, and the quantity of closed pores decreases. In comparison, the final porosity of the type $\mathrm{C}$

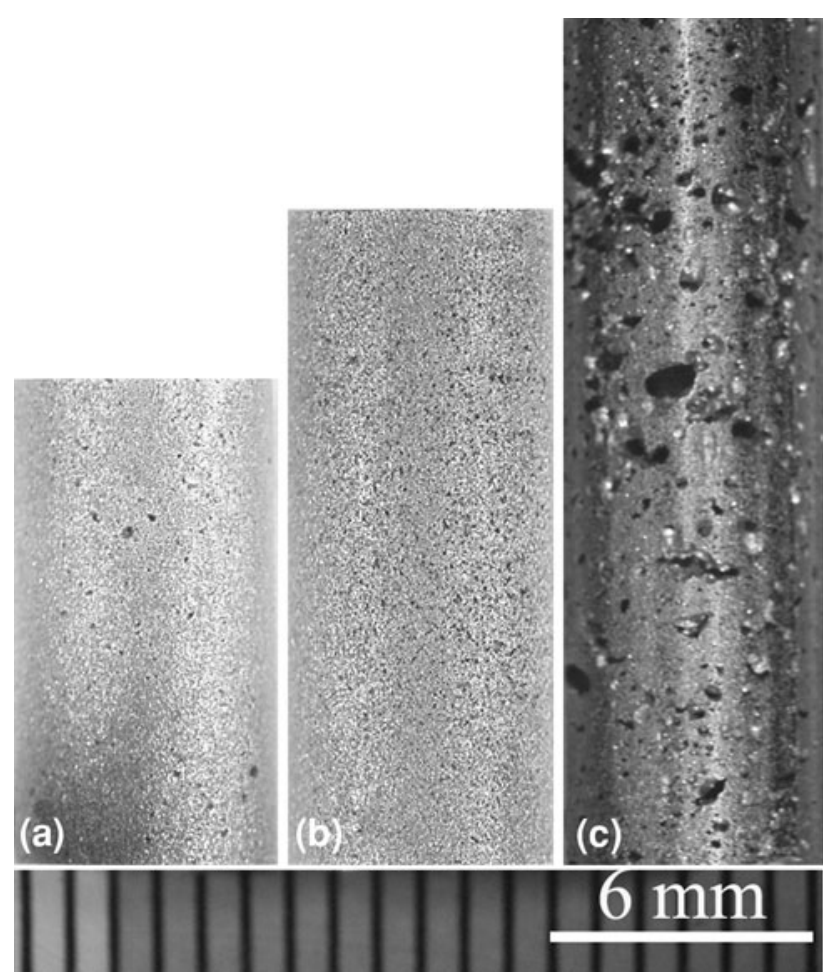

Fig. 2 Stereo optical macrographs of porous samples: (a) type A; (b) type B; and (c) type C 


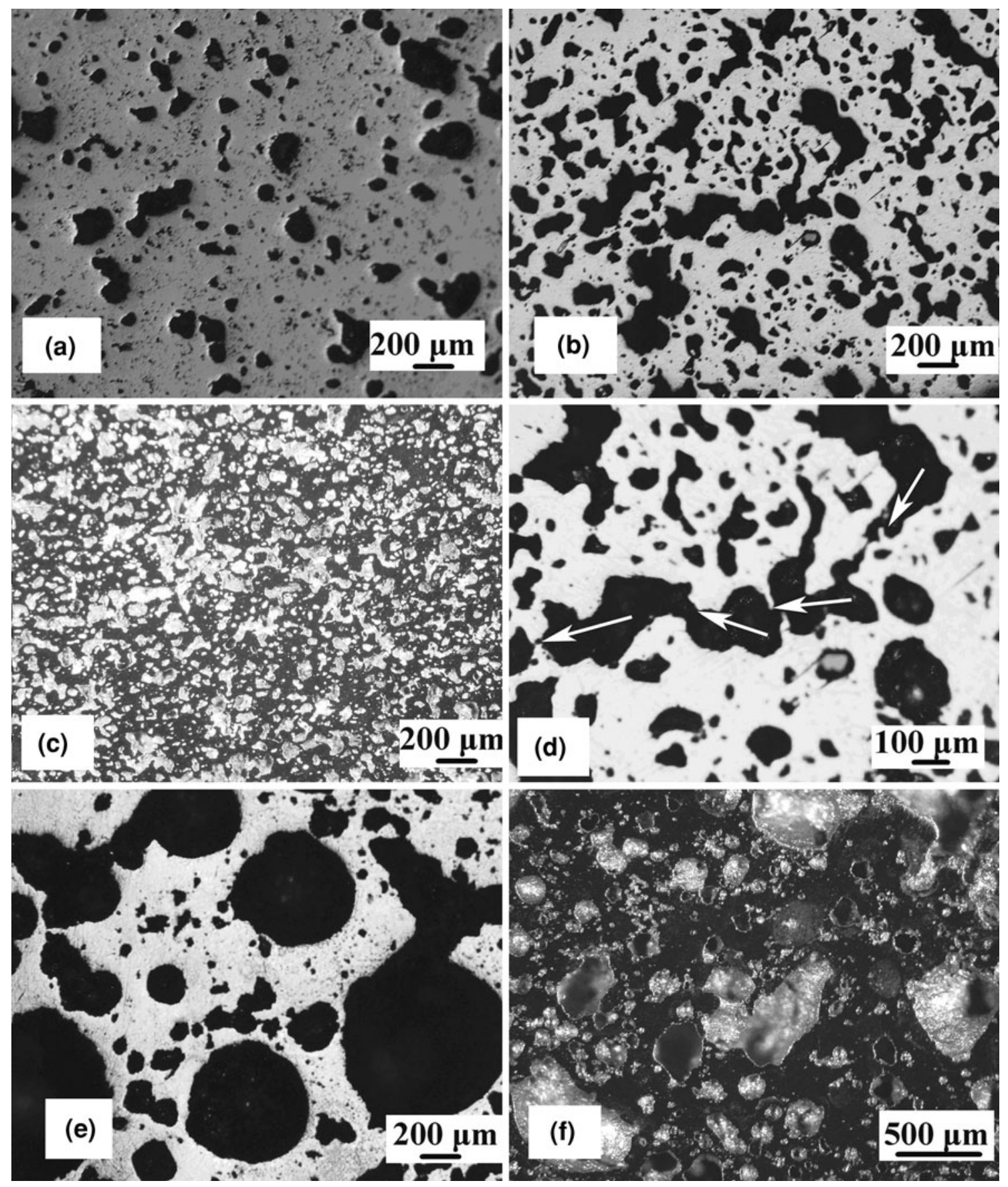

Fig. 3 Optical photographs of as-sintered porous NiTi: (a) type A; (b) type B; (c) stereo optical micrograph of type B; (d) high-magnification micrograph of (b); (e) type C; and (f) stereo optical micrograph of type C

samples increases to about $48 \%$ because its corresponding green porosity after removing $\mathrm{NH}_{4} \mathrm{HCO}_{3}$ is about $66 \%$ that is much higher than that of the type B samples. Figure 2(a)-(c) shows the optical macrographs of the as-sintered porous NiTi type $\mathrm{A}$, type $\mathrm{B}$. and type $\mathrm{C}$ samples produced from the corresponding green compacts at a cold compaction of $200 \mathrm{MPa}$, respectively. It is obvious that both $\mathrm{TiH}_{2}$ and $\mathrm{NH}_{4} \mathrm{HCO}_{3}$ can further improve the final porosity of the as-sintered samples, while the latter can effectively change the pore size.

Figure 3 shows the microstructures of the as-sintered type A samples with $28 \%$ porosity as well as the type B and type
C samples made from the corresponding green compacts at a cold compaction of $200 \mathrm{MPa}$. It can be observed that the pores in the porous NiTi sintered from green compacts without $\mathrm{TiH}_{2}$ are near circular and separate (shown in Fig. 3a). The open porosity of this sample is about $20 \%$ as measured by the ASTM B328-96 protocol (Ref 21) indicating that most of the pores are closed. It is believed that these closed pores are derived from the original pores in the green compacts. The formation of the other $20 \%$ open pores is possibly due to the penetration of high pressure argon gas during CF-HIP. In comparison, the open porosity of the type B samples is about $60 \%$ because diffusion of $\mathrm{H}_{2}$ can 
significantly improve the interconnection between separate pores (shown in Fig. 3b, c). Figure 3(d) illustrates the formation of the interconnected pores. In addition to the penetration of high pressure argon, high pressure $\mathrm{H}_{2}$ can easily pierce the wall between separate pores in a soft medium at a high sintering temperature (indicated by the arrows in Fig. 3d). Figure 3(a) and (b) reveals that the sizes of most of the pores range from 20 to $200 \mu \mathrm{m}$, suggesting that $\mathrm{TiH}_{2}$ has little effects on the pore size of the porous NiTi. It can be found in Fig. 3(e) and (f) that most of the pores in the type $\mathrm{C}$ samples are near circular have sizes ranging from 50 to $800 \mu \mathrm{m}$. The results suggest that besides the porosity, the space holder $\mathrm{NH}_{4} \mathrm{HCO}_{3}$ can also significantly improve the pore size but does not affect the pore shape compared with the type A samples. This is because $\mathrm{NH}_{4} \mathrm{HCO}_{3}$ can increase the number and size of the original pores in the green compacts upon removal. Hence, there are more Ar-filled pores with larger sizes in the type $\mathrm{C}$ samples resulting in the increase of the porosity and pore size after sintering. Furthermore, the addition of $\mathrm{NH}_{4} \mathrm{HCO}_{3}$ also sharply increases the open porosity of the as-sintered porous samples. The open porosity of the type $\mathrm{C}$ samples produced by the same protocol ( $\operatorname{Ref} 21$ ) is about $70 \%$ indicating that most of the pores are interconnected.

Figure 4 shows the phase compositions of the porous NiTi produced by CF-HIP. Several intermetallic compounds composed mainly of the intended B2 (austenite NiTi) and B19 (monoclinic martensite NiTi) phases together with minor second phases such as $\mathrm{Ni}_{3} \mathrm{Ti}, \mathrm{Ti}_{2} \mathrm{Ni}$, and $\mathrm{Ni}_{4} \mathrm{Ti}_{3}$. NiTi constitutes the major phase because of the equiatomic Ni-Ti composition of the green compacts before sintering according to the Ni-Ti binary diagram (Ref 22). The appearance of the second phases is a common phenomenon in the powder metallurgical processes of NiTi alloy (Ref 12, 14, 23), and it can be attributed to the composition fluctuation caused by the insufficient mixing of the raw powders and small particle size of the reagent powders (Ref 24). It is very difficult to completely remove some of the secondary phases such as $\mathrm{Ni}_{3} \mathrm{Ti}$ by solid-state diffusion because it is thermodynamically more stable than TiNi (Ref 23). It can be concluded from Fig. 4 that additions of $\mathrm{TH}_{2}$ and $\mathrm{NH}_{4} \mathrm{HCO}_{3}$ do not influence the phase components of the porous NiTi.

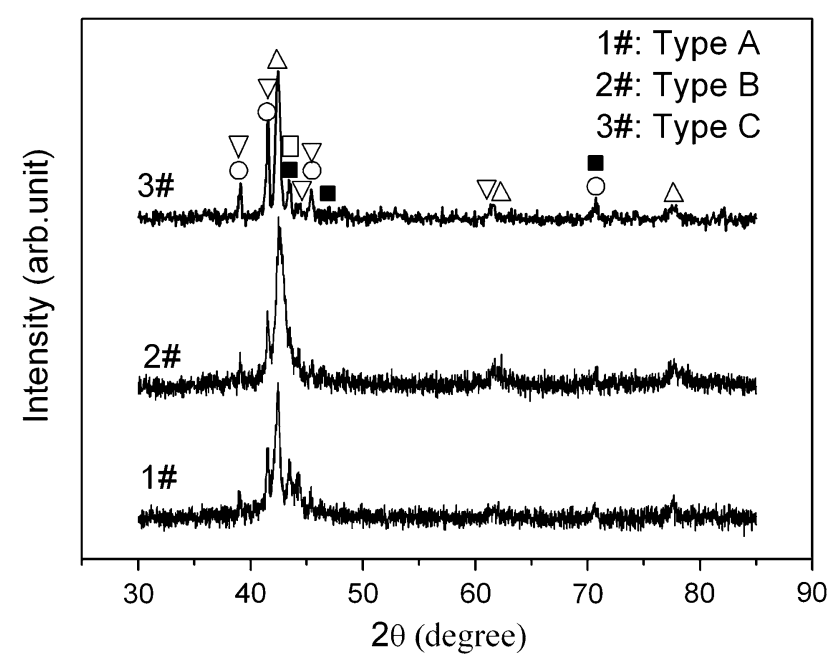

Fig. 4 Phase components of porous NiTi types A, B, and C. $\Delta$ : B2 (NiTi); $\nabla: \mathrm{B} 19^{\prime}$ (NiTi); $\mathbf{\square}: \mathrm{Ni}_{3} \mathrm{Ti} ; \bigcirc: \mathrm{Ti}_{2} \mathrm{Ni} ; \square: \mathrm{Ni}_{4} \mathrm{Ti}_{3}$
The compressive stress-strain results of the porous NiTi are shown in Fig. 5. The compressive strength of the type A samples is about $270 \mathrm{MPa}$ when strained up to $3.5 \%$, and the residual strain is about $0.05 \%$ after unloading, whereas the corresponding strength and residual strain of the type B samples are $220 \mathrm{MPa}$ and $0.1 \%$, respectively. In addition, curve 1 exhibits an obvious stress-plateau, but curve 2 does not show it clearly. The data suggest that $\mathrm{TiH}_{2}$ addition to the green compacts slightly impairs the compression strength and superelasticity of the porous NiTi. This is because $\mathrm{TiH}_{2}$ addition not only improves the porosity but also interconnects the separate closed pores. In comparison with type A and type C samples, the irregular pore shape in type B samples (shown in Fig. 3) would be harmful to the mechanical properties of porous NiTi alloys. The corresponding strength and residual strain of the type C samples are about $130 \mathrm{MPa}$ and $0.12 \%$, respectively, when strained up to $2.8 \%$. It is well accepted that the similar Young's modulus with human bone favors the smooth transfer of a load and thus is beneficial to the formation of new bone tissues on the implants $(\operatorname{Ref} 4,8)$. As is known, some hard tissues like bone and tendon possess superelastic behavior, i.e., their stress-strain curves can exhibit stress-plateau despite the extension of stain. Therefore, the mechanical properties of both type $\mathrm{A}$ and type $\mathrm{C}$ samples are more similar to natural bone than those of type $\mathrm{C}$ samples. The Young's moduli of the porous samples can be calculated in the near-linear region by Hooke's Law, i.e., $E=\sigma / \varepsilon$, where $E$ represents the elastic modulus, and $\sigma$ is the stress when the strain value reaches to $\varepsilon$. According to the stress-strain curves in Fig. 5, the Young's moduli of type A, type B, and type C samples are 8.648, 5.06, and $6.445 \mathrm{GPa}$, respectively, which are very close to the value of natural bone. According to the reported results (Ref 25, 26), the Young's modulus of cancellous bones is in the range of 1-2 GPa, while the value of wet compact human bones varies from 11.5 to $17.0 \mathrm{GPa}$. Compared with porous NiTi fabricated by other methods (Ref 12,14,16), the porous NiTi prepared by CF-HIP exhibits higher compression strength, high strain recovery, and narrower hysteretic loop because during the CF-HIP process, the high pressure argon gas prevents densification and enhances bridging among particles. The evolution of the compressed argon gas inside the compact helps in eliminating the microcracks. Although Zhao et al. (Ref 27) have reported that porous NiTi with $13 \%$ porosity fabricated by

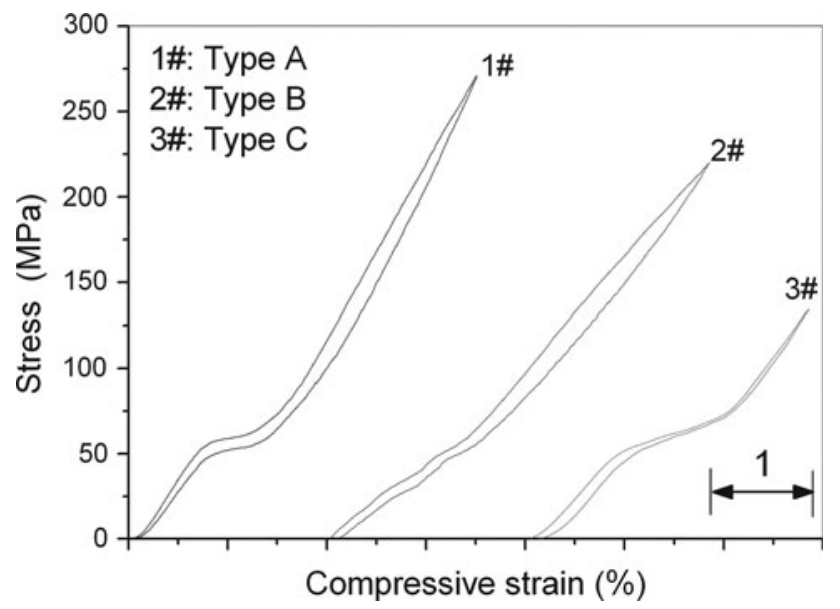

Fig. 5 Compressive stress-strain curves of porous NiTi type A, B and $\mathrm{C}$ 


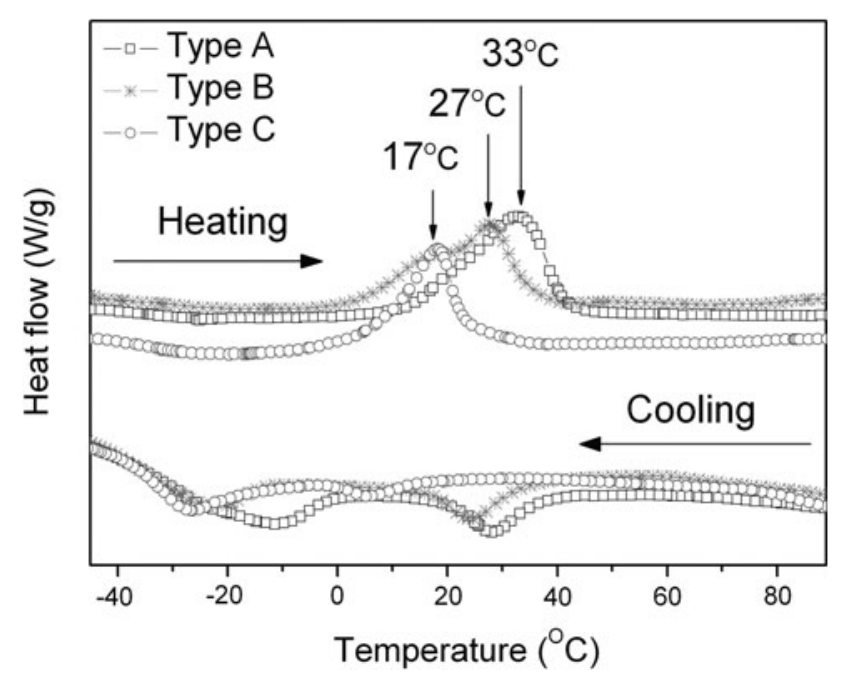

Fig. 6 DSC curves of porous NiTi annealed at $450{ }^{\circ} \mathrm{C}$ for $1 \mathrm{~h}$

spark plasma sintering (SPS) shows higher compression strength and excellent SE similar to those of dense NiTi, the compression strength of their $25 \%$ porosity sample is much lower than that of our type $\mathrm{C}$ sample with $48 \%$ porosity. This also confirms that porous NiTi fabricated by CF-HIP can have good mechanical properties in conjunction with higher porosity.

Figure 6 shows the DSC curves of the porous NiTi annealed at $450{ }^{\circ} \mathrm{C}$ for $1 \mathrm{~h}$. There are two transformation peaks in the cooling curves, namely, B2 $\rightarrow \mathrm{R}$ and $\mathrm{R} \rightarrow \mathrm{B} 19^{\prime}$, as well as one broadened B19' $\rightarrow$ B2 transformation peak in the reverse direction. Comparing the three types of samples, it is evident that the transformation temperatures shift to lower values with increased porosities. This is possibly due to the non-uniform internal stress caused by pore's expansion. The internal stress increases with higher porosities and suppresses martensite transformation. Figure 6 shows that the transformation temperatures of the samples of types A, B, and C are favorable from the viewpoint of the human body's temperature.

\section{Conclusions}

In summary, porous NiTi has been successfully fabricated by CF-HIP. The porosity is adjustable by changing the cold compaction pressure of the green compacts, $\mathrm{TiH}_{2}$, or $\mathrm{NH}_{4} \mathrm{HCO}_{3}$ addition. Compared with materials synthesized by other methods, the porous NiTi produced by CF-HIP exhibits higher compression strength and excellent $\mathrm{SE}$ in addition to the higher porosity. The transformation temperatures of the three types of porous NiTi favor superelasticity at the human body temperature thereby boding well for the use of the materials in orthopedic corrections.

\section{Acknowledgments}

This study was jointly supported by City University of Hong Kong Applied Research Grant (ARG) No. 9667038, National Natural Science Foundation of China No. 50901032, 51101053, Ministry of Education Specialized Research Foundation for Doctoral Program of Universities No. 20094208120003, Hubei
Provincial Middle-Young Research Fund Grant no. Q20101010, and Wuhan ChenGuang Research Program Grant no. 201150431134.

\section{References}

1. L.S. Castleman, S.M. Motzkin, F.P. Alicandri, V.L. bonawit, and A.A. Johnson, Biocompatibility of Nitinol Alloy as an Implant Material, J. Biomed. Mater. Res., 1976, 10(5), p 695-731

2. X.M. Liu, S.L. Wu, Y.L. Chan, P.K. Chu, C.Y. Chung, C.L. Chu, K.W.K. Yeung, W.W. Lu, K.M.C. Cheung, and K.D.K. Luk, Surface Characteristics, Biocompatibility, and Mechanical Properties of Nickel-Titanium Plasma-Implanted with Nitrogen at Different Implantation Voltages, J. Biomed. Mater. Res. A, 2007, 82(2), p 469-478

3. S.J. Li, R. Yang, S. Li, Y.L. Hao, and Y.Y. Cui, Formation and Growth of Calcium Phosphate on the Surface of Oxidized Ti-29Nb-13Ta-4.6Zr Alloy, Biomaterials, 2004, 25(13), p 2525-2532

4. J.A. Helsen and B.H. Jurgen, Ed., Metals as Biomaterials, John Wiley \& Sons, New York, 1998

5. S.L. Wu, C.Y. Chung, X.M. Liu, P.K. Chu, J.P.Y. Ho, C.L. Chu, Y.L. Chan, K.W.K. Yeung, W.W. Lu, K.M.C. Cheung, and K.D.K. Luk, Pore Formation Mechanism and Characterization of Porous NiTi Shape Memory Alloys Synthesized by Capsule-Free Hot Isostatic Pressing, Acta Mater., 2007, 55(10), p 3437-3451

6. S.L. Wu, X.M. Liu, T. Hu, P.K. Chu, J.P.Y. Ho, Y.L. Chan, K.W.K. Yeung, C.L. Chu, T.F. Hung, K.F. Huo, C.Y. Chung, W.W. Lu, K.M.C. Cheung, and K.D.K. Luk, A Biomimetic Hierarchical Scaffold: Natural Growth of Nanotitanates on Three-Dimensional Microporous Ti-Based Metals, Nano Lett., 2008, 8(11), p 3803-3808

7. V.I. Itin, V.E. Gyunter, S.A. Shabalovskaya, and R.L.C. Sachdeva, Mechanical-Properties and Shape-Memory of Porous Nitinol, Mater. Charact., 1994, 32(3), p 179-187

8. X.M. Liu, S.L. Wu, K.W.K. Yeung, Y.L. Chan, T. Hu, Z.S. Xu, X.Y. Liu, J.C.Y. Chung, K.M.C. Cheung, and P.K. Chu, Relationship Between Osseointegration and Superelastic Biomechanics in Porous NiTi scaffolds, Biomaterials, 2011, 32(2), p 330-338

9. O. Prymak, D. Bogdanski, M. Koller, S.A. Esenwein, G. Muhr, F. Beckmann, T. Donath, M. Assad, and M. Epple, Morphological Characterization and In Vitro Biocompatibility of a Porous NickelTitanium Alloy, Biomaterials, 2005, 26(29), p 5801-5807

10. A.J. Neurohr and D.C. Dunand, Shape-Memory NiTi with TwoDimensional Networks of Micro-Channels, Acta Biomater, 2011, 7(4), p 1862-1872

11. Y.H. Li, L.J. Rong, and Y.Y. Li, Compressive Property of Porous NiTi Alloy Synthesized by Combustion Synthesis, J. Alloys Compd., 2002, 345(1-2), p 271-274

12. C.L. Chu, C.Y. Chung, P.H. Lin, and S.D. Wang, Fabrication and Properties of Porous NiTi Shape Memory Alloys for Heavy LoadBearing Medical Applications, J. Mater. Process. Technol., 2005, 169(1), p 103-107

13. B.Y. Li, L.J. Rong, and Y.Y. Li, Porous NiTi Alloy Prepared from Elemental Powder Sintering, J. Mater. Res., 1998, 13(10), p 2847-2851

14. B.Y. Li, L.J. Rong, and Y.Y. Li, Stress-Strain Behavior of Porous Ni-Ti Shape Memory Intermetallics Synthesized from Powder Sintering, Intermetallics, 2000, 8(5-6), p 643-646

15. S.L. Wu, X.M. Liu, K.W.K. Yeung, T. Hu, Z.S. Xu, J.C.Y. Chung, and P.K. Chu, Hydrogen Release from Titanium Hydride in Foaming of Orthopedic NiTi Scaffolds, Acta Biomater, 2011, 7(3), p 1387-1397

16. J.S. Kim, J.H. Kang, S.B. Kang, K.S. Yoon, and Y.S. Kwon, Porous TiNi Biomaterial by Self-Propagating High-Temperature Synthesis, Adv. Eng. Mater., 2004, 6(6), p 403-406

17. D.C. Lagoudas and E.L. Vandygriff, Processing and Characterization of NiTi Porous SMA by Elevated Pressure Sintering, J. Intell. Mater. Syst. Struct., 2002, 13(12), p 837-850

18. B. Yuan, C.Y. Chung, and M. Zhu, Microstructure and Martensitic Transformation Behavior of Porous NiTi Shape Memory Alloy Prepared by Hot Isostatic Pressing Processing, Mater. Sci. Eng. A, 2004, 382(1-2), p 181-187 
19. M. Nanko, K. Ishizaki, and T. Fujikawa, Porous Ceramic Filters Produced by Hot Isostatic Pressing, J. Am. Ceram. Soc., 1994, 77(9), p 2437-2442

20. S.L. Wu, P.K. Chu, X.M. Liu, C.Y. Chung, J.P.Y. Ho, C.L. Chu, S.C. Tjong, K.W.K. Yeung, W.W. Lu, K.M.C. Cheung, and K.D.K. Luk, Surface Characteristics, Mechanical Properties, and Cytocompatibility of Oxygen Plasma-Implanted Porous Nickel Titanium Shape Memory Alloy, J. Biomed. Mater. Res. A, 2006, 79(1), p 139-146

21. ASTM, Standard Test Method for Density, Oil Content, and Interconnected Porosity of Sintered Metal Structural Parts and Oil Impregnated Bearings, B328-96, ASTM Standard, ASTM, PA, 2003

22. T.B. Massalski, H. Okamoto, P.R. Subramanian, and L. Kacprzak, Binary Alloy Phase Diagrams, ASM International, Materials Park, OH, 1990, p 2874
23. J.C. Hey and A.P. Jardine, Shape-Memory TiNi Synthesis from Elemental Powders, Mater. Sci. Eng. A, 1994, 188(1-2), p 291-300

24. B.Y. Li, L.J. Rong, Y.Y. Li, and V.E. Gjunter, Synthesis of Porous Ni-Ti Shape-Memory Alloys by Self-Propagating High-Temperature Synthesis: Reaction Mechanism and Anisotropy in Pore Structure, Acta Mater., 2000, 48(15), p 3895-3904

25. L.J. Gibson and M.F. Ashby, Ed., Cellular Solids, Cambridge Press, Cambridge, 1997

26. W. Suchanek and M. Yoshimura, Processing and Properties of Hydroxyapatite-Based Biomaterials for Use as Hard Tissue Replacement Implants, J. Mater. Res., 1998, 13(1), p 94-117

27. Y. Zhao, M. Taya, Y.S. Kang, and A. Kawasaki, Compression Behavior of Porous NiTi Shape Memory Alloy, Acta Mater., 2005, 53(2), p 337343 